\title{
Correction: Active teachers' perceptions on the most suitable resources for teaching history
}

\author{
Catalina Guerrero-Romera, Raquel Sánchez-Ibáñez, Ainoa Escribano-Miralles \& Verónica Vivas-Moreno (1)
}

Correction to: Humanities and Social Sciences Communications https://doi.org/10.1057/s41599-021-00736-7, published online 4 March 2021

The original version of this Article contained an error in the author name Verónica Vivas-Moreno, which was incorrectly given as Verónica Vivas Vivas-Moreno. This has now been corrected in both the PDF and HTML versions of the Article.

Published online: 24 March 2021

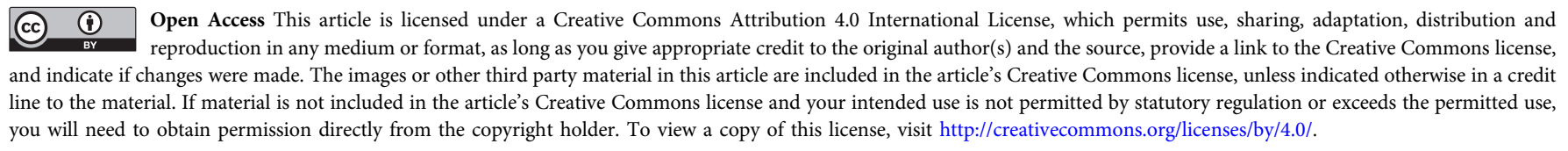

(c) The Author(s) 2021 